\title{
Business Decisions In A Cooperative Environment
}

Eric Jessup, (E-mail: Jessup.wsu.edu), Washington State University Ken Casavant, (E-mail: casavantk@wsu.edu), Washington State University Jason Monson, Washington State University Ken Duft, Washington State University

\section{Background}

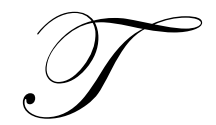

he trend for cooperative consolidation in the grain industry continues to be common throughout the United States. In the state of Washington, for example, the total number of agribusiness cooperatives has decreased by nearly $40 \%$ over the past 3 decades. Grain cooperatives in eastern Washington have diminished by $30 \%$ over this same period, and by $60 \%$ over the past 55 years (Monson, 2003). The bulk of this reduction in numbers may be attributed to mergers and consolidations, but a few liquidations are also evident. While many factors have contributed towards this long-standing trend, most would argue that a persistence of "economies of size" appears as a dominant force encouraging industry restructuring at almost every level. The incentive and motivation to lower long-run average total costs by increasing size, capacity and volume is present for both types of grain agribusinesses (cooperatives and private (or publicly) owned businesses) while the implicit objective function for these different business forms is slightly different. The primary objective for privately owned businesses is to maximize profit, subject to a constraint on technology which may be influenced by the private firm's access to capital and management expertise. A cooperative operates under a slightly different objective, namely, maximizing patron service subject to assuring equal representation of all members, size and support of cooperative members, access to financial capital, access to management leadership and maintaining longrun financial viability, as detailed below.

\section{Max [Patron Service $] \quad$ Subject to :}

- Equal Representation

- Available Membership

- Access to Capital

- $\quad$ Management Leadership

- $\quad$ Long-Run Financial Viability

Throughout the past three decades it has been presumed that while cooperatives have slightly different objective functions as compared to privately owned firms, they must operate and compete in the marketplace using similar tactical management business decisions including facility reorganization and warehouse consolidation. This trend presumably has afforded eastern Washington's grain industry a lower per unit cost and enhanced their financial performance and long-run survival ability, thus satisfying the cooperative's objective of maximizing patron service. However, the existence of this particular concept and practice has not been tested. This concept also presumes that "economies of size" for grain cooperatives are continuous throughout, where increasing size, alone, never becomes a detriment to firm performance or maximizing member service. Neither has been tested. It is easier to document that handling and storage capacity within the grain cooperative sector is well in excess of annual production volume. The impact of unused capacity on cooperatives achieving economies of size also remains untested. The objectives of the research reported on here were to address these three questions.

\section{Cooperative Structure}

Eastern Washington Grain cooperatives and country elevators have historically provided their membership with valuable service through enhanced marketing alternatives and improved bargaining power. However, the 
ability of these non-profit organizations to provide service value to their member patrons while operating and competing against profit maximizing firms may prove challenging in the future. In the Northwest, most grain cooperatives were established in the 1930's to access economies of size in storage and shipping which producers could not access individually (Hays, 1986). Grain cooperative consolidation now appears to be influenced by these same profit maximizing / economic principles as their numbers continue to decrease. While the number of grain cooperatives has decreased, according to an industry survey ${ }^{1}$ (Monson, 2003), the total cooperative storage and handling capacity has increased by $312 \%$ since 1947. In 1947, for example, 57 grain cooperatives controlled $70 \%$ of the licensed warehouse capacity in Washington and competed against 52 private companies. By 2001/02, 52 grain companies remained, 22 of which were cooperatives, and their total grain storage capacity had increased to $211,592,000$ bushels. These changes are indicative of cooperative business decisions that resulted in more efficient storage consolidation and enhanced storage capabilities for cooperative members.

While cooperatives represented just $40 \%$ of the grain companies operating warehouses in eastern Washington, by $2001 / 02$ they accounted for $81 \%$ of the existing licensed warehouse capacity. The remaining $19 \%$ reflected the storage capacity of public or private companies. Total grain storage capacity was afforded by a total of 413 houses (elevators), of which 309 were operated by cooperative organizations. Licensed storage capacity reported by those cooperatives ranged from 960,000 to $26,606,000$ bushels and averaged 7,790,682 per organization. Individual house capacities ranged from 10,000 to 5,659,000 bushels and the number of houses per cooperative ranged from 1 to 46 . The average number of houses and locations per cooperative was 14.05 and 9.27 respectively, and the average volume per house was 554,676 bushels. Eastern Washington's storage capacity for all grains, including on-farm storage, is $286,144,300$ bushels. As noted above, cooperative storage capacity is $211,592,000$ bushels (Monson, 2003). According to Washington Agriculture Statistics, the 12 year wheat and barley average production is $160,044,000$ and $28,965,000$ bushels, respectively. As such, storage capacity is $50 \%$ in excess of that required to handle total production, assuming that all production is stored following harvest.

In large measure, grain cooperatives provide a service, i.e. the storage, handling and merchandising of their patrons' grain. Service provider concentration, therefore, is evidenced by the fact that the largest 4 cooperatives control $47 \%$ of the volume and manage $49 \%$ of the houses. The largest 8 cooperatives provide $71 \%$ of licensed capacity and $72 \%$ of the houses. The structure of the industry is further impacted by the productivity of the adjacent lands and the volume of annual crop production. There are 3,014 one thousand acre or larger grain farms in the 20 eastern Washington counties and $47 \%$ of those are located in Adams, Grant, Lincoln, and Whitman counties. Within this four-county area, grain farms account for $63 \%$ of on-farm storage and $58 \%$ of cooperative storage capacity. Current on-farm storage capacity throughout eastern Washington is estimated to be 74,552,300 (Edwards and Jessup, 1998) and represents a 521\% increase over that which existed in 1948 (Dooley, 1980).

\section{Cooperative Performance:}

In general, market performance is described as the end result of market adjustments made between buyers and sellers. Performance measures include, but are not limited to, financial data such as ratios and comparative cost functions. And, given the influence of U.S. government agricultural policies on grain cooperative revenues, those revenues, cost structures and investment decisions must be included in any measures of performance.

Six years of financial statements were successfully collected from 20 of the 22 grain cooperatives operating in eastern Washington. The contents of the financial statements provide a map for better understanding the economic position and historical financial performance of the grain industry and specifically service oriented cooperatives. Cooperative respondents were further subdivided into three size categories, based on licensed capacity (see Table 1.1). A compilation of financial data by size of respondent cooperative provided a basis upon which to judge performance within the traditional categories of liquidity, profitability, and solvency. (Assume from this part forward that profitability actually refers to a cooperative's operating margin.)

\footnotetext{
${ }^{1}$ This survey reflects $100 \%$ of the industry's structural characteristics and its financial data is based on a $76 \%$ response rate.
} 
Table 1.1. Cooperative Size Categories According to Licensed Capacity

\begin{tabular}{lcccccccc}
\hline $\begin{array}{l}\text { Size } \\
\text { Category } \\
(\mathbf{1 . 0 0 0} \text { Bu) }\end{array}$ & $\begin{array}{c}\text { Number } \\
\text { of } \\
\text { Co-ops }\end{array}$ & $\begin{array}{c}\text { Percent } \\
\text { of } \\
\text { Total } \\
\text { Co-ops }\end{array}$ & $\begin{array}{c}\text { Total } \\
\text { Co-op } \\
\text { Capacity } \\
\text { (Bu) }\end{array}$ & $\begin{array}{c}\text { Percent of } \\
\text { Co-op } \\
\text { Total } \\
\text { Capacity }\end{array}$ & $\begin{array}{c}\text { Total } \\
\text { Co-op } \\
\text { Locations }\end{array}$ & $\begin{array}{c}\text { Percent } \\
\text { of Co-op } \\
\text { Total } \\
\text { Locations }\end{array}$ & $\begin{array}{c}\text { Total } \\
\text { Co-op } \\
\text { Houses }\end{array}$ & $\begin{array}{c}\text { Percent } \\
\text { of Total } \\
\text { Co-op } \\
\text { Houses }\end{array}$ \\
\hline $\begin{array}{l}\text { Small, } \\
0-3,000\end{array}$ & 5 & $25.00 \%$ & $7,979,000$ & $4.584 \%$ & 11 & $5.73 \%$ & 18 & $6.14 \%$ \\
$\begin{array}{l}\text { Medium, } \\
3,001-\end{array}$ & 7 & $35.00 \%$ & $49,383,000$ & $28.374 \%$ & 53 & $27.60 \%$ & 80 & $27.30 \%$ \\
$\begin{array}{l}8,500 \\
\text { Large, }\end{array}$ & 8 & $40.00 \%$ & $116,684,000$ & $67.042 \%$ & 128 & $66.67 \%$ & 195 & $66.55 \%$ \\
$\begin{array}{l}8,501- \\
26,500\end{array}$ & & & & & & & & \\
\hline Total & $\mathbf{2 0}$ & $\mathbf{1 0 0 . 0 \%}$ & $\mathbf{1 7 4 , 0 4 6 , 0 0 0}$ & $\mathbf{1 0 0 . 0 0 \%}$ & $\mathbf{1 9 2}$ & $\mathbf{1 0 0 . 0 0 \%}$ & $\mathbf{2 9 3}$ \\
\hline
\end{tabular}

Liquidity is essential for cooperatives to provide quality service to their member-patrons and eastern Washington grain cooperatives have maintained a strong liquidity position. Large cooperatives maintained their current assets over the 6 year study period, showing only a slight $2 \%$ decline. Small and medium size cooperatives, however, reported current assets values which decreased by half over this same time period. Fortunately, current liabilities for small and medium sized cooperatives decreased by an even greater percentage, 80 and $60 \%$ respectively. In fact, medium sized cooperatives reported the highest average current ratio of 7.2, with small and large cooperatives reporting 6.0 and 2.0 , respectively.

The profitability of grain cooperatives declined significantly during the observation period (1997-2002). This was evident in the form of declining gross revenue, net operating margin, and total volume intake. Medium sized cooperatives appeared to suffer the most, recording a $105 \%$ decrease in net income. However, large and small grain cooperatives also reported significant decreases (at $81 \%$ and $73 \%$, respectively). As might be expected, gross revenue reflected the decline in volume of grain received. Average profit margins were similar amongst the different size groups of reporting cooperatives. For example, the average profit margins for small, medium and large firms were $\$ .017, \$ .013$ and $\$ .014$ per dollar of gross revenue. Average total costs, per bushel handled, were the same (\$.31) for both medium and small cooperatives. Surprisingly, it was the larger cooperatives that reported higher average total costs of $\$ .50$ per bushel handled, suggesting that larger scale cooperatives provide greater breadth of services when compared to smaller cooperatives. Similarly, medium and small cooperatives had a higher grain turnover than their larger counterpart, while the total grain intake declined most for small (78\%) and medium (42\%) sized firms. Insofar as large cooperatives appeared able to attract grain from a larger geographical region, they experienced only a slight $(2 \%)$ decline in volume over the observation period.

Returns to assets measures the dollars of net income earned per dollar of assets employed. Medium sized cooperatives provided the greatest average return to total assets $(\$ .06)$, followed by large and small cooperatives (at $\$ .05$ and \$.04). Finally, it appeared that as licensed capacity increased, so did the ratios of net income and total intake to licensed capacity, in bushels.

Solvency improved for small cooperatives from 1997-2002, with a 58\% reduction in the ratio of total debts to patron's equity. Corresponding to this general reduction of debt, the owners' percent of equity improved and suggested an increased reliance on member capital relative to borrowed funds. Similar reductions in the debt ratios were reported by the medium sized firms. However, a reverse trend was observed with large cooperatives reporting a $28 \%$ increase in the debt ratio and a $62 \%$ increase in their ratio of total debts to patron's equity. It appeared that larger cooperatives were less solvent over the study period, as evidenced by their heavier reliance on borrowed capital. Despite this declining solvency, large cooperatives were able to report a $\$ .07$ net income per dollar of patron's equity. In contrast, small cooperatives reported only $\$ .04$. Large cooperatives were also able to generate more net income with less capital invested in storage facilities. 


\section{Cooperative Efficiency}

An average cost frontier function representing the long run average cost of cooperatives was mapped from the contents of the annual financial reports to determine the degree of economies of size in the cooperative grain industry. Generally speaking, economies of size exist when average costs fall as output increases (given some level of fixed inputs). It should be noted that economies of scale imply that all inputs vary in constant proportions, but economies of size are not restricted to such a condition. In any case, economies of size more accurately reflect the structure of the grain industry where input increases are rarely proportionate in magnitude. As evidenced by Figure 1.1 and Table 2.1, the long run average cost curve depicts operating costs that decrease as volume handled increases. The level of grain volume corresponding to the minimum point for the concentrated grain firms is $10,119,976$ bushels, at an average cost per bushel of \$.0478. The LRAC curve represents the employment of current technology, operating costs and capital investment of the reporting cooperatives.

It should be noted that the U-shaped average total cost curve shows that economies of size do exist amongst the grain cooperatives classified as "concentrated". Concentrated grain cooperatives are those operations that provide no extra services besides grain handling, storage and merchandising. In this case the existence of substantial economies of size is clearly present throughout the cooperative grain industry.

Figure 1.1. Long-Run Average Total Cost Curve for Concentrated Grain Cooperatives

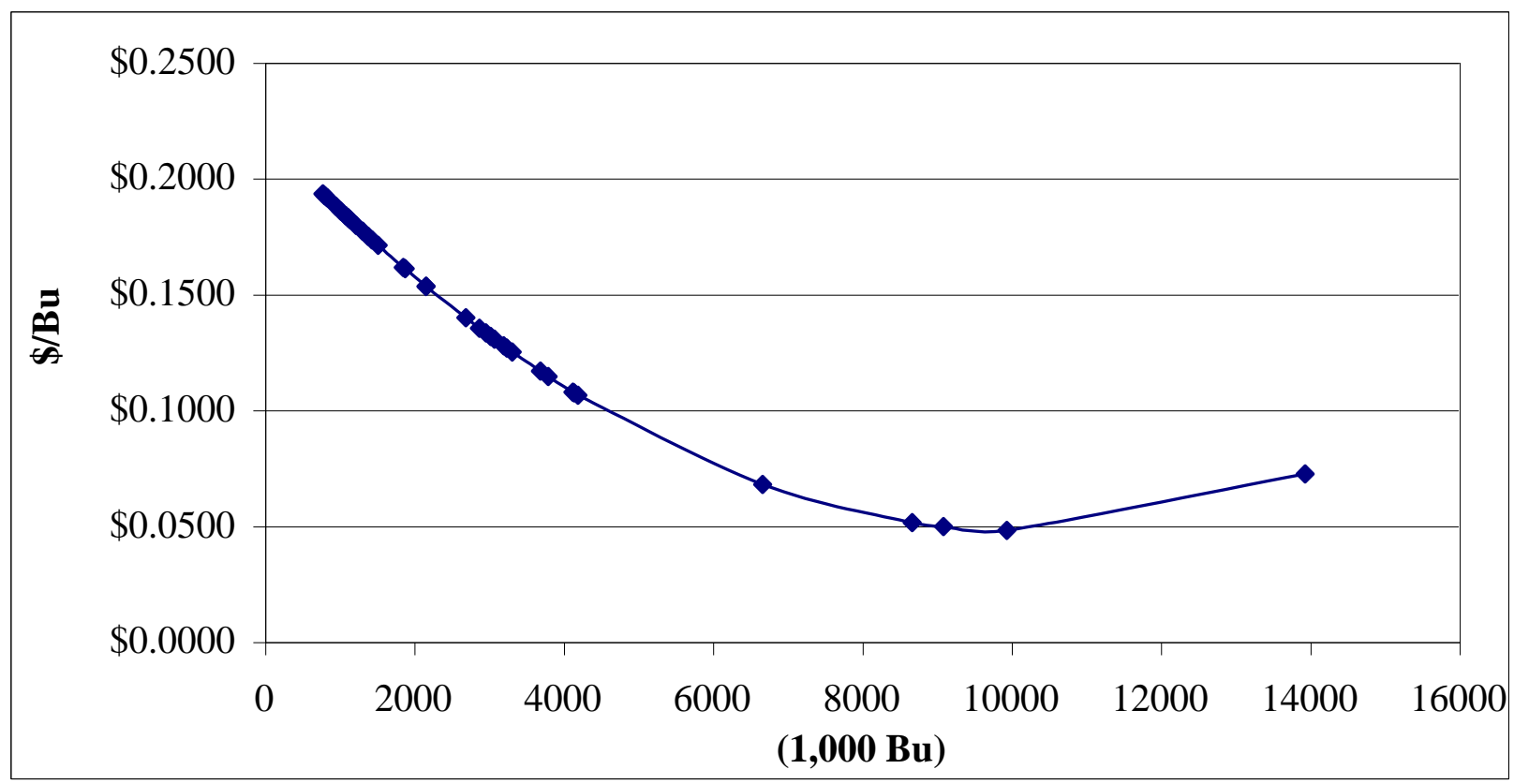

Table 2.1. 1997-2002 Time Series Average Liquidity Ratios According to Cooperative Size

\begin{tabular}{lccc}
\hline Ratio & Small Co-op & Medium Co-op & Large Co-op \\
\hline Current Ratio & 6.022 & 7.947 & 2.015 \\
\hline Acid Test Ratio & 4.965 & 7.234 & 1.102 \\
\hline Working Capital & & & 0.212 \\
\hline Total Intake (Bu) & 0.260 & 0.274 & \\
\hline Adapted From: $1997-2002$ cooperation
\end{tabular}

Adapted From: 1997-2002 cooperative financial statements. 


\section{Conclusion}

Grain cooperatives in eastern Washington have historically provided considerable value and service to its grain producing members through consolidated market power, operating cost advantages that translate into improved prices to member patrons, and increased marketing alternatives. They continue to provide these critical functions in the grain industry and agribusiness sector while operating and competing with profit maximizing firms that are not affected by the legal, institutional and structural constraints faced by cooperatives. The uniquely different objective function of maximizing member value and service for cooperatives has ultimately resulted in business decisions that are quite similar to profit maximizing firms, and operational outcomes that continue to serve the financial longevity of grain cooperatives. Indications of these cooperative business decisions and results are evident in the cooperative structure, performance and efficiency received in this analysis.

In search of further economies of size, cooperatives are consolidating at a notable rate. While their numbers continue to diminish, these organizations continue to add value to farmer output, provide high quality service to their member-patrons, and most importantly, guarantee healthy competition in an industry which might otherwise be subject to oligopolistic influence.

The singular functions of receiving, storing and merchandising grain do not afford cooperative management many competitive options. Neither are they confronted with a broad array of means for altering their internal operational cost structure. Yet the industry continues to change, adapt and innovate. Industry structure continues its three-decade long evolution through consolidation. Cooperative performance remains financially strong, but increasingly reliant on volume through-put, quality service, government farm programs, and attempts to capture efficiencies linked to economies of size. Industry segmentation by function (diversified vs. specialized) suggests that each is impacted by volume considerations, but to differing degrees.

\section{References}

1. Dooley, Frank J. "Theory and Economics of Multiplant Firms Applied to Washington Grain Elevator Firms." Ph.D. dissertation, Dept. of Agricultural Economics, Wash. State University, Pullman, August 1986.

2. $\quad$ Edwards, Richard and Eric L. Jessup. "Eastern Washington On-Farm and Commercial Grain Storage." EWITS Research Report Number 20. Dept. of Agri. Econ., Wash State U., Pullman, WA, January 1998.

3. $\quad$ Farm Service Agency. "Summary for Active Contracts for all Program Years (1987-2004)." USDA, Farm Service Agency, Washington D.C., 2002. Downloaded from http://www.fsa.usda.gov/crpstorpt/12approved/r1sumyr/wa.htm.

4. Hays, John Joseph. "Structure, Conduct, and Performance of Grain Handling Firms in the Country Elevator Industry in Washington.” M.A. thesis, Dept. of Agri. Econ., Wash. State U., Pullman, May 1986.

5. Jorgens, John Robert Stuart. "Grain Handling-Storage Costs of Country Warehouses in Washington." M.A. thesis, Dept. of Agri. Econ., The State College of Washington, 1949.

6. Kansas City Commodity Office. Annual grain storage revenue received by grain cooperatives in Washington State, 1998-2002. Kansas City, KS, 2002.

7. Kansas City Commodity Office. Grain Warehouse Data Report. Kansas City, KS, September 24, 2002.

8. Monson, Jason, "The Changing Dynamics of Grain Cooperatives in Eastern Washington." Department of Agricultural and Resource Economics, Washington State University, M.A. Thesis, May 2003

9. Richards, Timothy J. and Mark R. Manfredo. "Cooperative Mergers and Acquisitions: The Role of Capital Constraints." J. Agriculture and Resource Economics, 28(1):152-168.

10. Washington State Department of Agriculture, Commodity Inspection Division. Public Grain Warehouses. Olympia, WA, various issues, 1990-2002.

11. Washington State Department of Agriculture, Commodity Inspection Division, Washington Bonded Warehouse Rates and Charges, July 1, 2002. 
Notes 